\title{
Refractive Error and Anterior Segment Parametric Changes in Patients with Posterior Capsular Opacification after Nd: YAG Laser Posterior Capsulotomy
}

\author{
Mehdi Alizadeh', Nasrin Jiryaee², Milad Molaei ${ }^{3}$, Fatemeh Eslami ${ }^{1, *}$ \\ ${ }^{I}$ Assistant Professor, Department of Ophthalmology, School of Medicine, Hamadan University of Medical Sciences, \\ Hamadan, Iran \\ ${ }^{2}$ Assistant Professor, Department of Social Medicine, School of Medicine, Hamadan University of Medical Sciences, \\ Hamadan, Iran \\ ${ }^{3}$ General Practitioner, Hamadan University of Medical Sciences, Hamadan, Iran \\ * Corresponding Author: Fatemeh Eslami, Department of Ophthalmology, School of Medicine, Hamadan University of \\ Medical Sciences, Hamadan, Iran.Email: HRGB2005@yahoo.com
}

Received: 05.08.2019

Accepted: 17.11 .2019

How to Cite this Article: Alizadeh M, Jiryaee N, Molaei M, Eslami F. Refractive Error and Anterior Segment Parametric Changes in Patients with Posterior Capsular Opacification after Nd: YAG Laser Posterior Capsulotomy. Avicenna J Clin Med. 2019; 26(3): 166-172. DOI: $10.29252 / \mathrm{ajcm} .26 .3 .166$

\section{Abstract}

Background and Objective: Cataract is one of the most common causes of blindness in the world, and posterior capsular opacification (PCO) is the most common complication after cataract surgery. Nd: YAG laser posterior capsulotomy is a standard method for the treatment of PCO. The aim of this study was to investigate the effects of Yas laser capsulotomy on anterior segment parameters and lenticular astigmatism.

Materials and Methods: In this randomized clinical trial study, a total of 37 eyes from 30 patients with posterior capsular opacity after uneventful phacoemulsification were enrolled and underwent Nd: YAG laser capsulotomy. Full ocular examination, including intraocular pressure and refractive errors, was performed on the samples. The AC depth, volume, and angle were measured by Pentacam before capsulotomy and 3 months following that.

Results: Mean visual acuity improved preoperatively $(0.505 \pm 0.276)$ and 3 months after capsulotomy $(0.646 \pm 0.268)$; $(\mathrm{P}<0.001)$. Mean values of spherical equivalent and cylindrical powers were $1.304 \pm 0.268$ and $-1.142 \pm 0.881$ dioptre before the procedure and $1.285 \pm 0.152$ and $-1.027 \pm 0.807$ dioptre 3 months following the surgery, respectively. The difference in cylindrical and spherical errors was not statistically significant after the procedure. Mean scores of lenticular astigmatisms were $0.902 \pm 0.735$ and $0.621 \pm 0.326$ dioptre before and after capsulotomy, respectively, which was statistically significant $(\mathrm{P}=0.018)$. The changes in the Anterior Chamber depth, angle, volume, and mean central corneal thickness were not statistically significant after capsulotomy.

Conclusion: Laser capsulotomy decreased lenticular astigmatism and improved visual acuity. The changes in the AC depth might be a clue for associated complications, such as the changes in refractive errors, intraocular lens position, and intraocular pressure.

Keywords: Pentacam, Posterior Capsular Opacity, Refractive Error, YAG Laser Capsulotomy 


\section{تأثير ياتى ليزر كيسولوتومى بر هارامتر هاى سكمان قدامى و عيوب انكسارى در بيماران دجار كدورت كيسول خلفى}

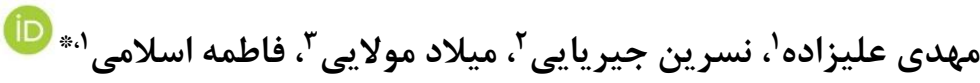

' استاديار، گَروه جشمريزشكى، دانشكده يزشكى، دانشخاه علوم يزشكى همدان، همدان، ايران

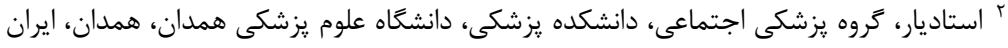

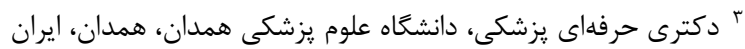

* * نويسنده مسئول: فاطمه اسلامى، كروه جشمريزشكى، دانشكده يزشكى، دانشعاه علوم يزشكى همدان، همدان، ايران. ايميل: yRGB2005@yahoo.com

\begin{tabular}{|c|c|}
\hline جكيده & \\
\hline 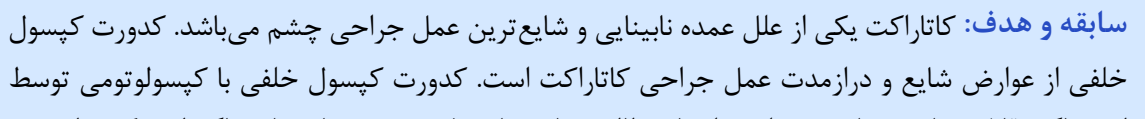 & 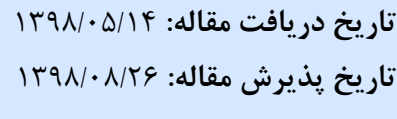 \\
\hline 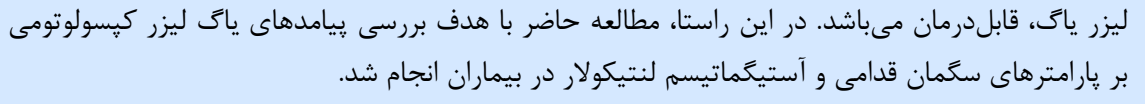 & تمامى حقوق نشر براى دانشكاه علوم \\
\hline مواد و روشها: در اين كار آزمايى بالينى تصادفىشده، در rV حشم از ·r بيمار سودوفاكيك دجار كدورت & \\
\hline كيسول خلفى مراجعه كننده به بيمار ستان سيناى همدان، يارامترهاى سخمان قدامى و آستيكماتيسم لنتيكولار، & \\
\hline يكى بار قبل و بار ديكر سه ماه پِس از ياكَ ليزر كِيسولوتومى اندازهگيرى شده و مورد تجزيه و تحليل قرار كَرفتند. & \\
\hline 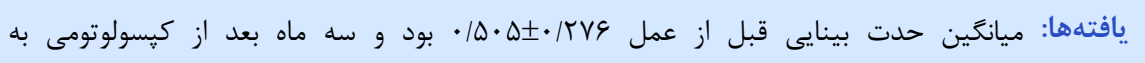 & \\
\hline 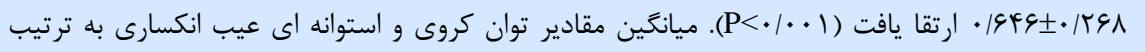 & \\
\hline & \\
\hline بعد از عمل جراحى بود. تفاوت عيوب انكسارى استوانه اي و كروى بعد از عمل از نظر آمارى معنى دار نبود. & \\
\hline 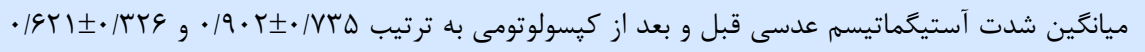 & \\
\hline 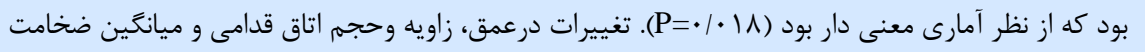 & \\
\hline مركزى قرنيه بِ از كيسولوتومى از نظر آمارى معنى دار نبود. & \\
\hline نتيجه كيرى: عمل ياك ليزر كيسولوتومى بهطور معنادارى باعث كاهش ميزان آستيخماتيسم لنتيكولار و & \\
\hline بهبود حدت بينايى بيماران نسبت به قبل از انجام عمل مى شود. تغيير در عمق اتاق قدامى مىتواند عامل & \\
\hline عوارض ناخواستهاى ماند تغيير در عيوب انكسارى، فشار داخل خشم و جابهجايى لنز باشد. & \\
\hline وازگَان كليدى: پينتاكم، عيب انكسارى، كدورت كيسول خلفى، ياك ليزر كيسولوتومى & \\
\hline
\end{tabular}

مقلدمه

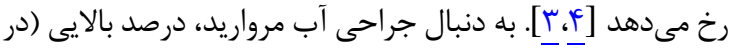

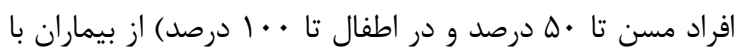
كذشت زمان متفاوتى (طى دو ماه تا ينج سال) به دماله

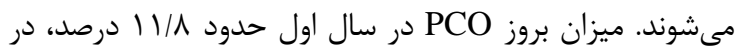

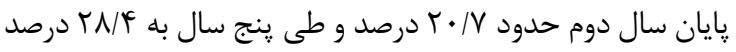

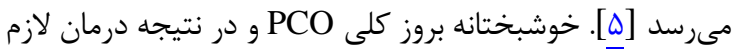

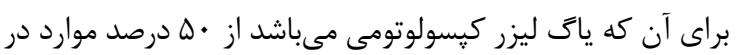

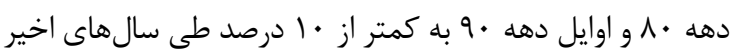

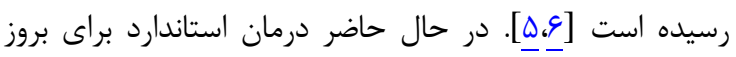

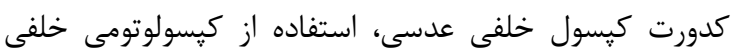
با ليزر Neodymium Yttrium Aluminum ) Nd:YAG
كاتاراكت يكى از دلايل عمده نابينايى در جهان است و

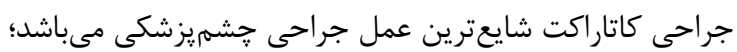

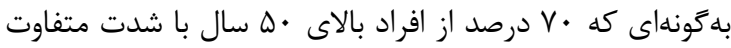

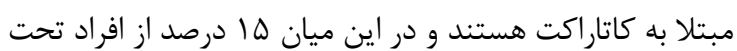

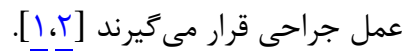

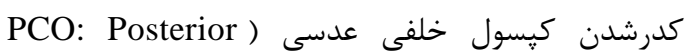
(Capsular Opacity كاتاراكت در هر دو روش فيكوامولسيفيكاسيون و جراحى خارئ نارج

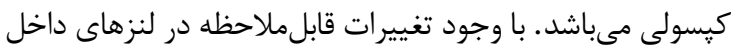

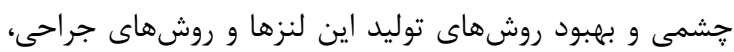

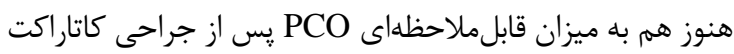


ميانگين در دو جامعه و مقادير مربوط به ميانخين و انحراف معيار

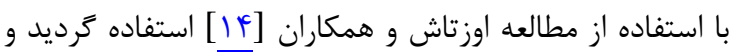
حجم نمونه نهايى معادل \&ץ نفر در نظر گرفته شد.

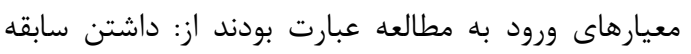
جراحى فيكو بدون عارضه، سيرىشدن وند حداقل شش ماه ماه از زمان

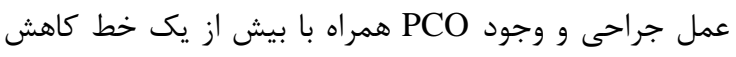

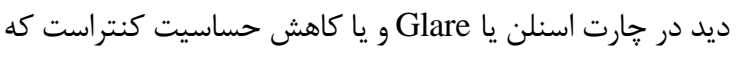
نياز به يات ليزر كيسولوتومى داشته باشد. در اين داين مطالعه

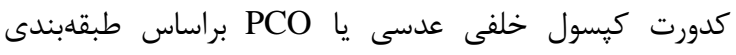
Sellman-Lindstrom به جهار گروه تقسيمبندى شد (جدول (1).

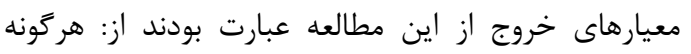

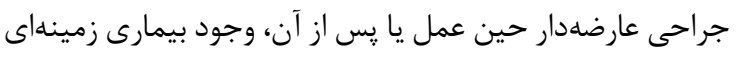

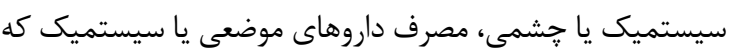

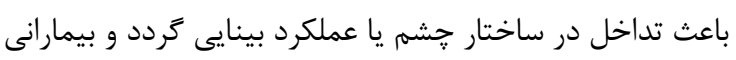

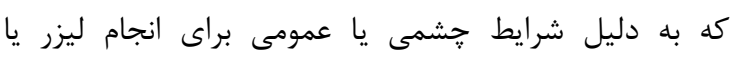
تصويربردارى سگمان قدامى همكارى نداشتند.

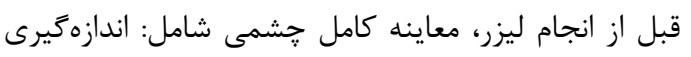

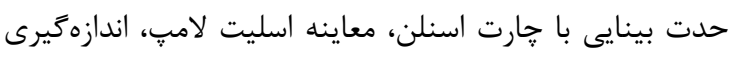

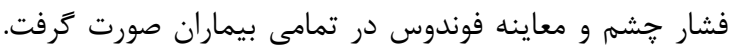

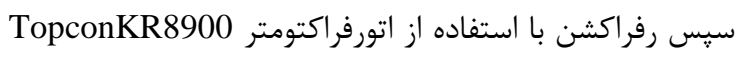

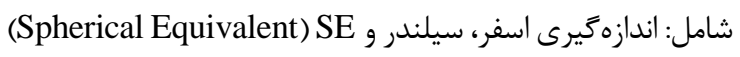
اندازهخيرى گرديد.

علاوهبراين پيارامترهاى سگمان قدامى شامل: ضخامت مركز

قرنيه، زاويه اتاق قدامى و حجم اتاق قدامى Central ) CCT Anterior Chamber) ACV ،Corneal Thickness

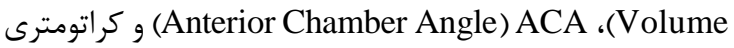
قرنيه با استفاده از دستخاه ينتاكم HR (ساخت شركت Oculus آلمان) در حالت غيرميدرياز اندازمخيرى شد. بهمنظور كنترل اثر دئر

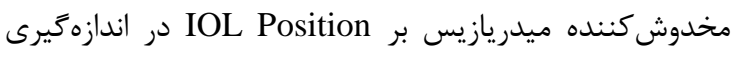

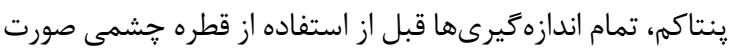

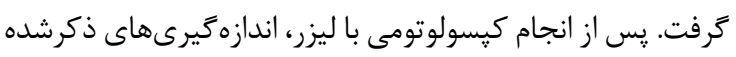
در يايان ماه سوم عيناً تكرار كرديد.

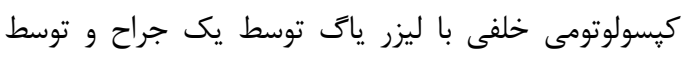

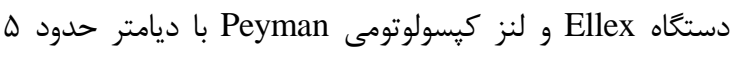
ميلى متر و بهصورت Circular Pattern صورت كرفت. همجنين بامنظور كنترل اثر مخدوش كننده سايز كيسولوتومى بر تشديد
(Garnet

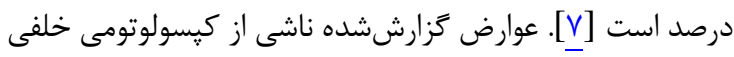

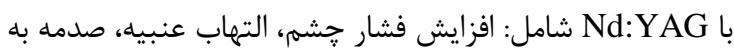

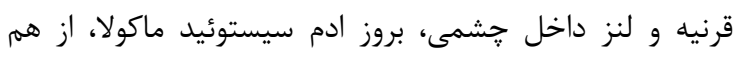

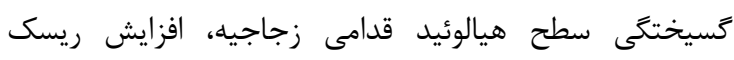

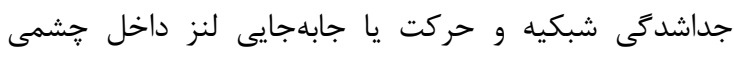

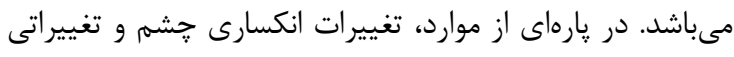

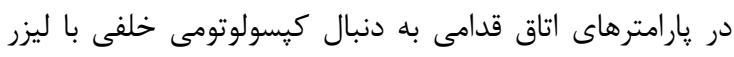
Nd:YAG

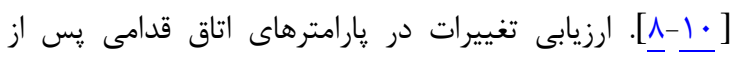

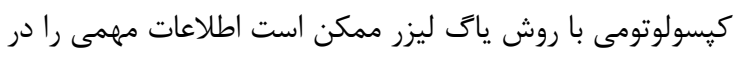

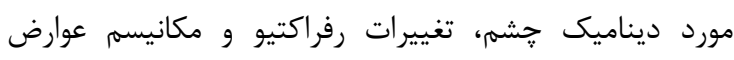
احتمالى بلهدست بدهد. در اين راستا در مطالعهاى كه توسط دئن

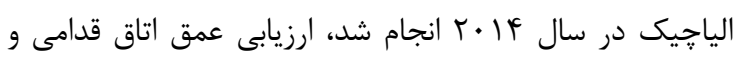

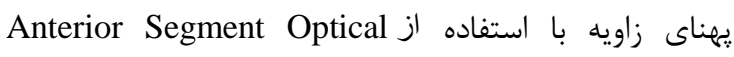
Coherence Tomography

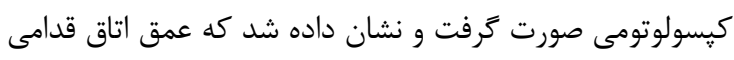

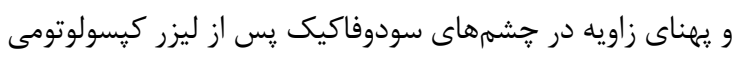

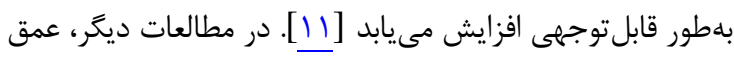

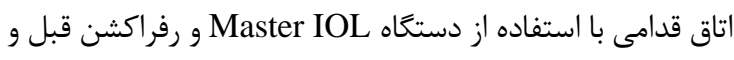
بعد از درمان در فواصل يكى هفته و سه ماه اندازهيرى شد كه

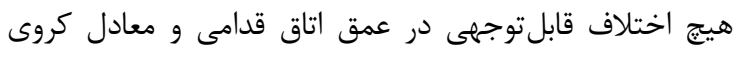

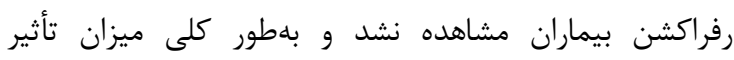

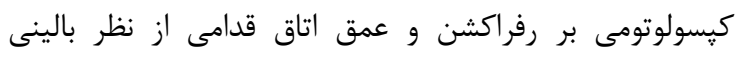

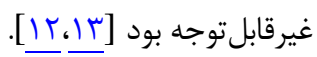

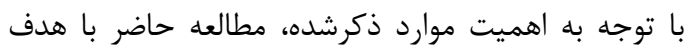

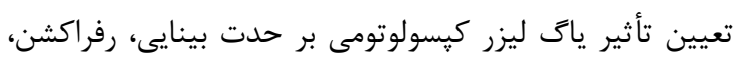

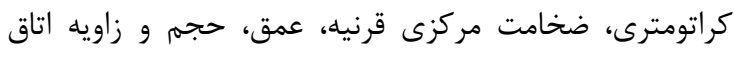

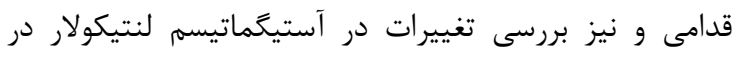
بيماران يسودوفاكيك دجار PCO مراجعه كننده به بيمار بيمارستان

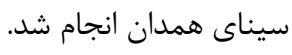

\section{مواد و روشها}

مطالعه حاضر از نوع كارآزمايى بالينى تصادفىشده مى باشد

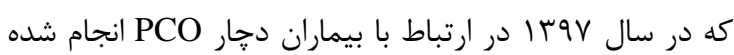

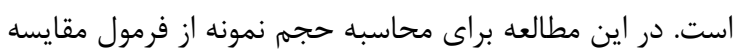

\begin{tabular}{|c|c|}
\hline Grade & Definition \\
\hline 1 & $\begin{array}{l}\text { No or slight PCO without reduced red reflex, also no } \\
\text { pearls at all or pearls not to the IOL edge }\end{array}$ \\
\hline 2 & $\begin{array}{l}\text { Mild PCO reducing the red reflex, Elschnig pearls to } \\
\text { the IOL edge }\end{array}$ \\
\hline 3 & $\begin{array}{l}\text { Moderate fibrosis or Elschnig pearls inside IOL edge } \\
\text { but with a clear visual axis }\end{array}$ \\
\hline 4 & $\begin{array}{l}\text { Severe fibrosis or Elschnig pearls covering the visual } \\
\text { axis and severely reducing the red reflex }\end{array}$ \\
\hline
\end{tabular}


و مدت زمان سيرىشده از انجام عمل كاتاراكت تا زمان انجام

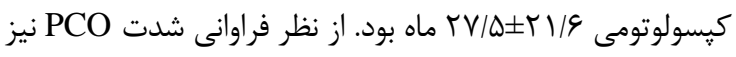

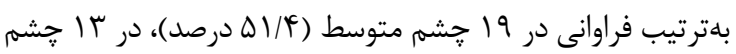

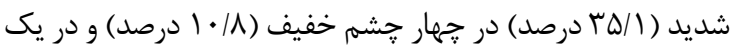

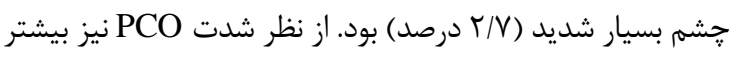
بيماران در گروه متوسط و شديد قرار داشتند.

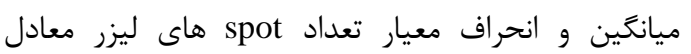

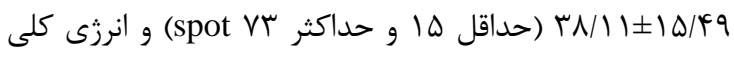
دستعاه ليزر برابر با

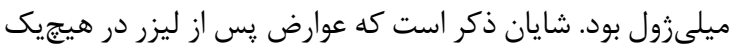

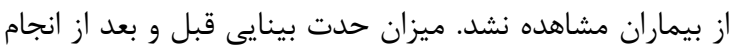

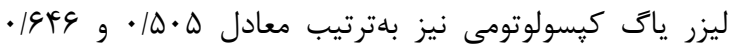

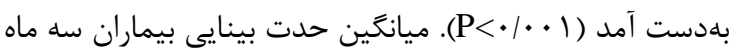

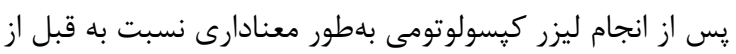

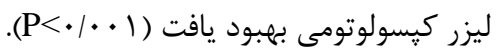

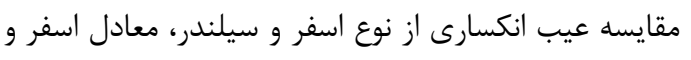

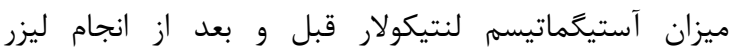

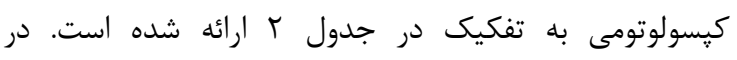

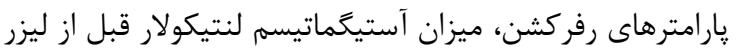

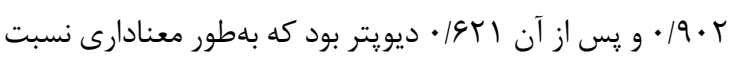

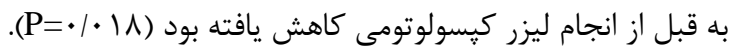

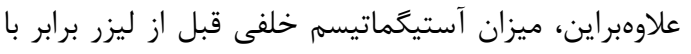

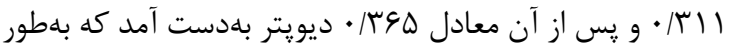

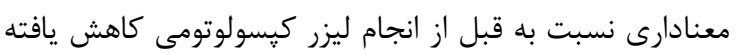

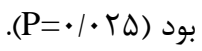
با توجه به نتايج ارائهشده در جدول باء ب و نتايج آزمون در
حركت IOL در تمام بيماران، سايز كيسولوتومى به اندازه حدود

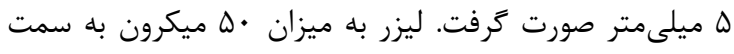
Posterior

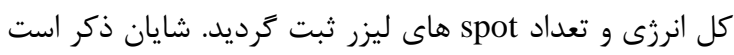

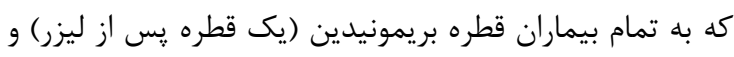

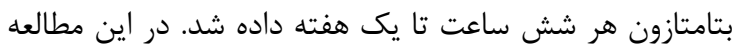

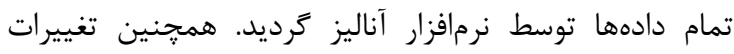

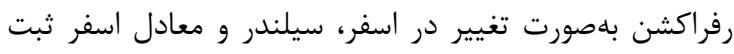

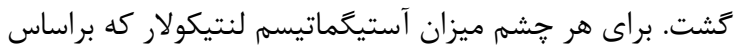

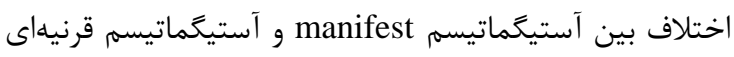

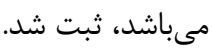
بايد خاطرنشان ساخت كه در بخش ند آمار توصيفى براى توصيف و كزارش متغيرهاى كمى با توزيع نرمال از ميانگين و انحراف معيار و براى متغيرهاى غيرنرمال از ميانه و دامنه ميان

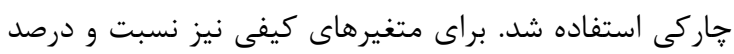

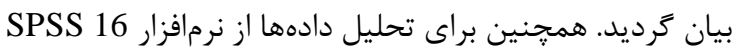

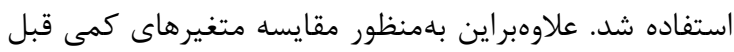

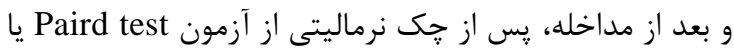
Wilcoxon يا Mann-Whitney Independent t -test سطح معنادارى آمارى نيز معادل ه درصد در نظر گرفته شد.

1افْته

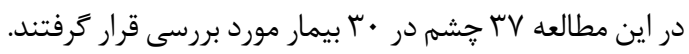

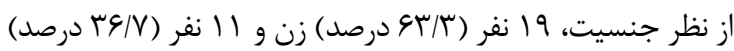

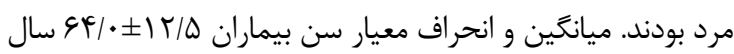

جدول ץ: مقايسه ميانگين و انحراف معيار متغيرهاى اندازمخيرىشده، قبل و سه ماه بعد از انجام كيسولوتومى

\begin{tabular}{|c|c|c|c|}
\hline سطح معنادارى & بعد از كيسولوتومى (rV جشمى) & قبل از كيسولوتومى (rV جشمه) & \\
\hline 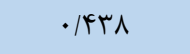 & $r / V Y \pm I / T I$ & $F / r T \pm 1 / T r$ & ميزان عيب انكسارى اسفر \\
\hline$\cdot|r| 9$ & $-1 / \cdot r V \pm \cdot / \Lambda \cdot V$ & $-I /|F T \pm \cdot| \Lambda \Lambda \mid$ & ميزان عيب انكسارى سيلندر \\
\hline$\cdot \operatorname{lag}$ & $\cdot / / \Delta T \pm I / r \wedge \Delta$ & $r / \varepsilon \wedge \pm 1 / r \cdot r$ & ميزان عيب انكسارى معادل اسفر \\
\hline$\cdot 1 \cdot 11$ & $\cdot|G T| \pm \cdot \mid r T S$ & $\cdot / 9 \cdot r \pm \cdot / V r \Delta$ & ميزان آستيخًماتيسم لنتيكولار \\
\hline .1119 & $r / q \uparrow r \pm \cdot / V I F$ & $F / \| I \pm \cdot V \Delta$. & عمق اتاق قدامى \\
\hline$\cdot / T V V$ & $\varphi \Delta / / \Lambda \pm N / G Y$ & $F Y / T \cdot \pm N / 9 q$ & يهناى زاويه اتاق قدامى \\
\hline$\cdot 19 \cdots$ & $\mid \varepsilon \Lambda / r \Lambda \pm r F / \cdot q$ & I $9 N / 9 T \pm Y N / A r$ & حجم اتاق قدامى \\
\hline.$/ 194$ & $\Delta q / / F \pm F / F q$ & $\Delta q / \Delta r \pm \Delta / r r$ & حجم قرنيه \\
\hline$\cdot / V G$ & $\Delta T / / 9 \Lambda \pm T \Delta / 1 T$ & $\Delta r \cdot \mid \Delta q \pm r V / \cdot r$ & ضخامت مركزى قرنيه \\
\hline$\cdot / 4 \& V$ & $-9 / 019 \pm \cdot / 01 T$ & $-q|\Delta r \cdot \pm \cdot| q \psi \cdot$ & ميزان كراتومترى خلفى \\
\hline - Mar & $F \Delta / \wedge \Delta V \pm r / r)$ & $F \Delta / 9 \uparrow q \pm r / / q 9$ & ميزان كراتومترى قدامى \\
\hline$\cdot / \cdot r \Delta$ & $\cdot / K \varphi \Delta \pm \cdot / T \mid V$ & $\cdot / T I I \pm \cdot / 1 V 9$ & ميزان آستيكماتيسم خلفى \\
\hline$\cdot / D F D$ & I/ $\uparrow \& \pm \cdot / \Lambda r V$ & $1 / \cdots \pm \cdot / \vee 94$ & ميزان آستيخماتيسم قدامى \\
\hline$\cdot|\Lambda| \Lambda$ & $\cdot \mid G Y K \pm \cdot / V F \Delta$ & $\cdot \mid 9 \wedge 9 \pm \cdot / \vee 9 \wedge$ & ميزان اختلاف آستيكماتيسم قدامى و خلفى \\
\hline$<\cdot / \cdot \bullet 1$ & - $1949 \pm \cdot \mid 948$ & $\cdot / \Delta \cdot \Delta \pm \cdot / T V G$ & حدت بينايى \\
\hline
\end{tabular}


آمارى معنادارى مشاهده نشد. در اين راستا در مطالعه اليجيك

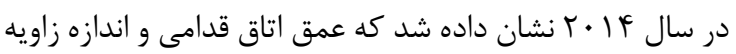

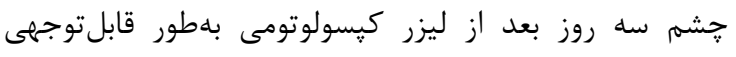

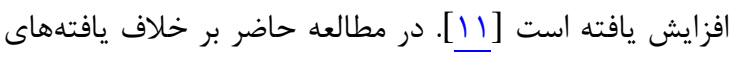

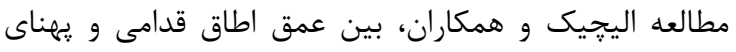

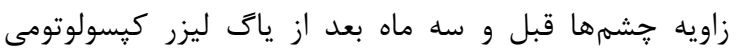
اختلاف آمارى معنادارى مشاهده نشد. اين احتمال وجود دارد فارد

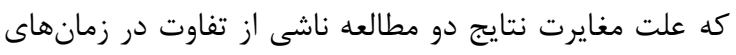

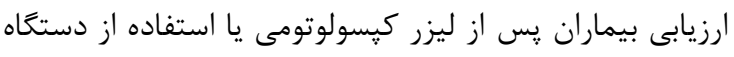
بCT

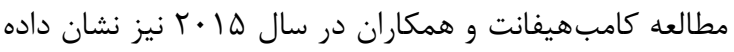

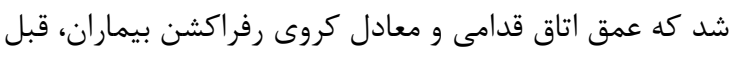

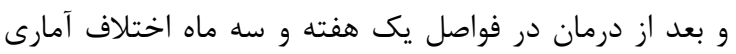

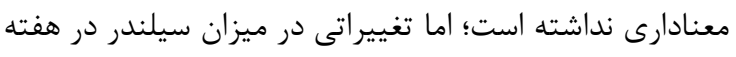

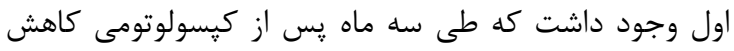
يافت. نوع IOL (يك تكهاى يا سه تكهاى) نيز تأثيرى بر نتايج

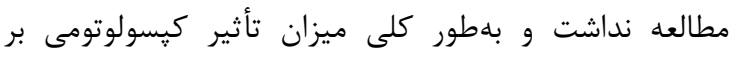

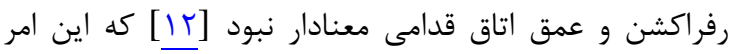

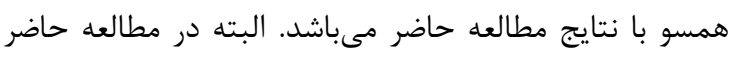
تمامى لنزهاى مورد استفاده از نوع يك تكهائ مطائ بودند. شايان

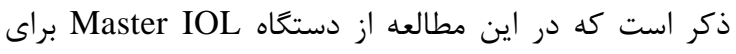
اندازهَيرى يارامترهاى اتاق قدامى استفاده شد.

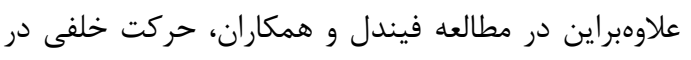

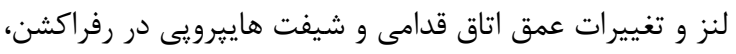

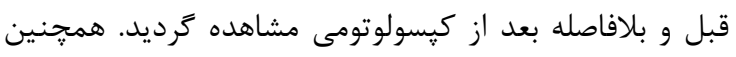
مشخص شد كه هرجه سايز كيسولوتومى بزر گتر باشد، ميزان

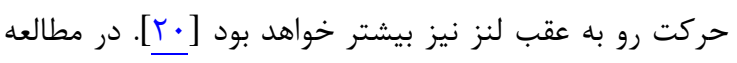
حاضر تغيير جزئى بهصورت كاهش در عمق اتاق قدامى به علت

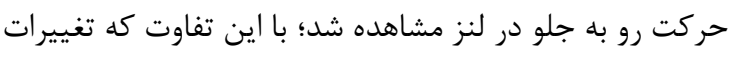
ACD كيسولوتومى و در مطالعه حاضر سه ماه يس از از يات لئ ليزر

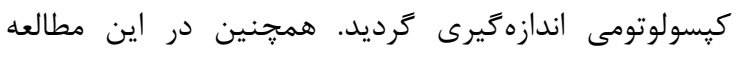

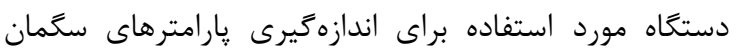
قدامى، Dual Beam Partial Coherence Interferometer بود كه حساسيتى در حد · f ميكرون دارد. حساسيت يايينتر

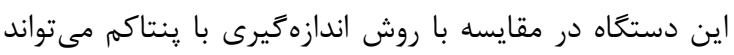
اختلاف موجود را توجيه كند. مطالعات متعددى در مورد دلايل تغييرات عمق اتاق قدامى رئ دون

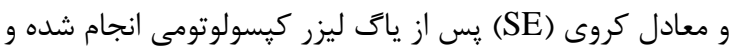

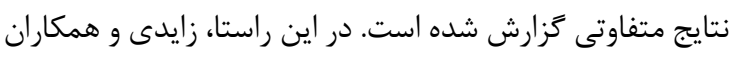

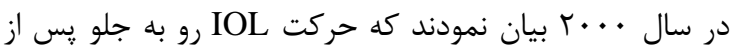

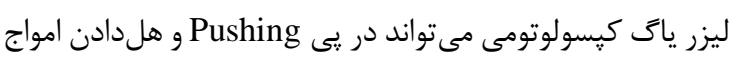

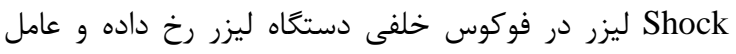

شيفت ميويى در رفركشن بيماران باشد [IV]
بيماران تحت مطالعه از نظر عمق، يهنا و حجم اتاق قدامى،

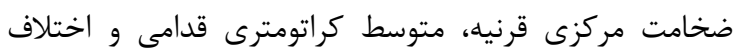
آستيگماتيسم قدامى و خلفى، قبل و سه ماه ماه يس إن از انجام ليزر

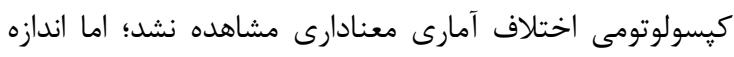

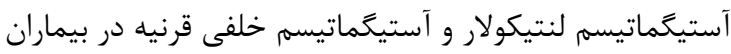

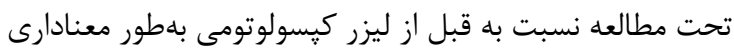

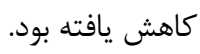

\section{بحث}

طبق برآورد سازمان جهانى بهداشت، آب مرواريد شايعترين

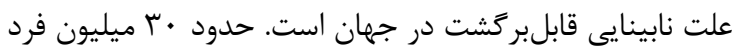

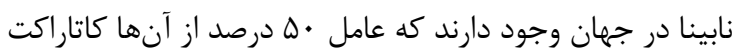

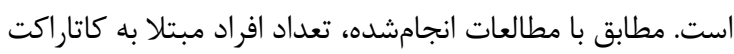

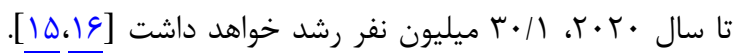

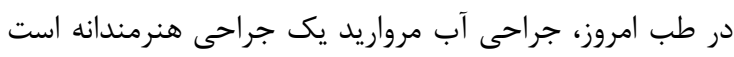

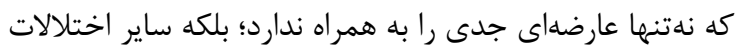

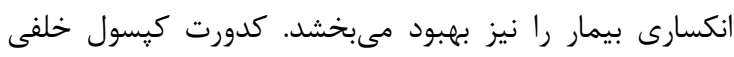

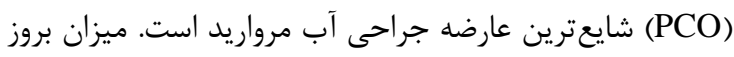

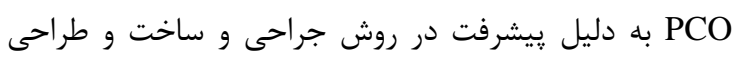

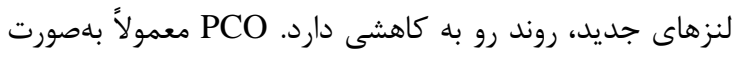

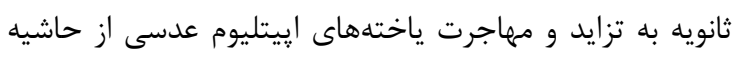

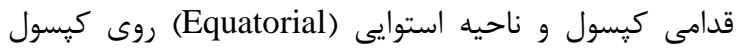

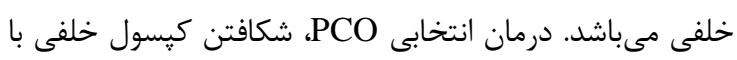

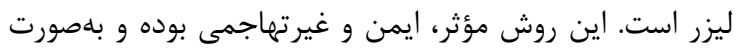

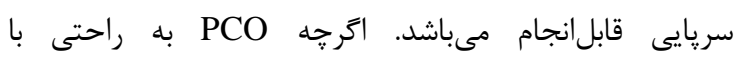

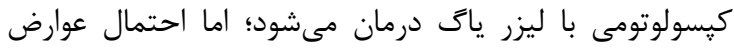

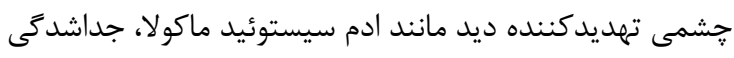

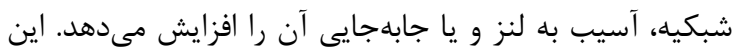

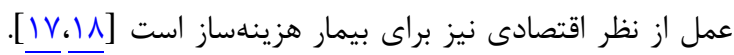

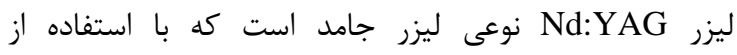
يونيزاسيون سبب از هم كسيختخى بافت مىشود. اين ليزر داراى ليز

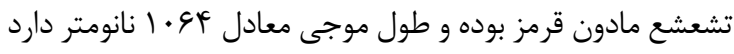

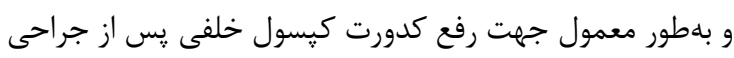

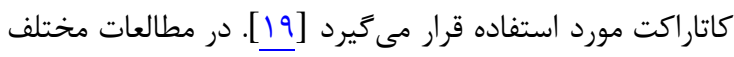

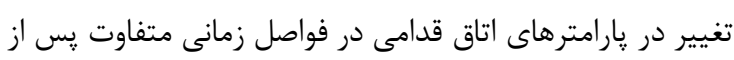

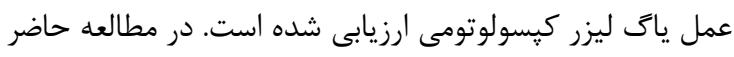

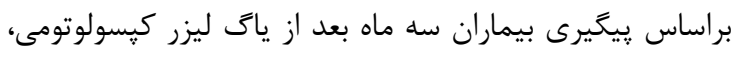

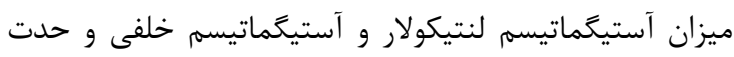

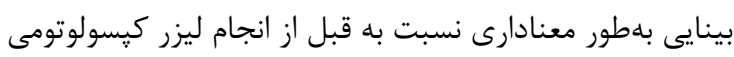

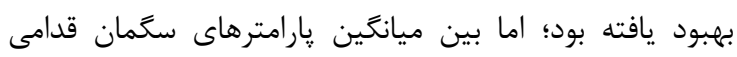

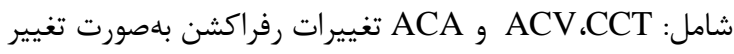

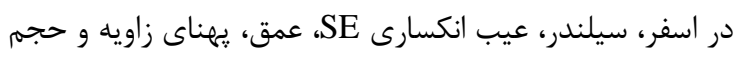

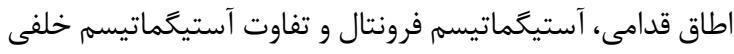

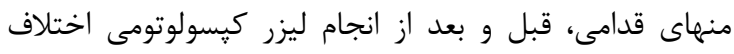


مىباشد. بدينوسيله نويسندگان مراتب قدردانى خود را از

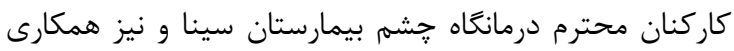

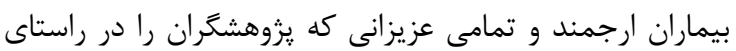
انجام اين مطالعه يارى رساندند، اعلام مىنمايند.

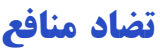
نتايج اين مطالعه با منافع نويسندكان در تعارض نمىباشد.

\section{ملاحظات اخلاقي}

مطالعه حاضر داراى تأييديه اخلاق در يزوهش با كد IR.UMSHA.REC.1398.050 همدان و كد IRCT20120215009014N288 از مركز ثبت كار آزمايى هاى بالينى ايران مىباشد.

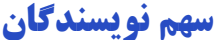

نويسنده اول (يزوهشكر اصلى): نغارش بخشهاى مقدمه،

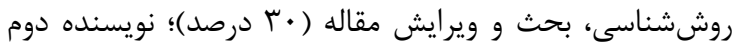

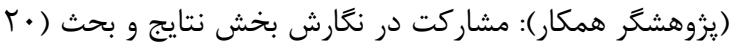

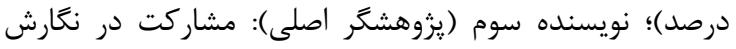

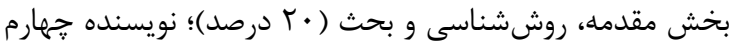
(يزوهشخر اصلى): تدوين بخش مقدمه، روش روسناسى و و بحث و

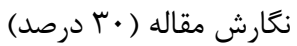

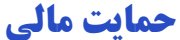

طرح حاضر از سوى معاونت تحقيقات و فناورى دانشگاه علوم يزشكى همدان يشتيبانى مالى شده است.

\section{REFERENCES}

1. Hashemi H, Alipour F, Fotouhi A, Alaeddini F, Rezvan F, Mehravaran S, et al. Iranian cataract surgery survey, design and study protocol. Iran J Ophthalmol. 2010;22(2):39-44.

2. Fotouhi A, Hashemi H, Mohammad K, Jalali KH. The prevalence and causes of visual impairment in Tehran: The Tehran Eye Study. Br J Ophthalmol. 2004;88(6):740-5. PMID: 15148203 DOI: $10.1136 /$ bjo.2003.031153

3. Riordan-Eva P, Whitcher JP. Vaughan \& Asbury's general ophthalmology. New York: McGraw-Hill; 2018.

4. Yotsukura E, Torii H, Saiki M, Negishi K, Tsubota K. Effect of neodymium: YAG laser capsulotomy on visual function in patients with posterior capsule opacification and good visual acuity. J Cataract Refract Surg. 2016;42(3):399-404. PMID: 27063520 DOI: 10.1016/j.jcrs.2015.11.042

5. Kahraman G, Amon M, Ferdinaro C, Nigl K, Walch M. Intraindividual comparative analysis of capsule opacification after implantation of 2 single-piece hydrophobic acrylic intraocular lenses models: three-year follow-up. J Cataract Refract Surg. 2015;41(5):990-6. PMID: 25953472 DOI: 10.1016/j.jcrs.2014.07.041

6. Polak M, Zarnowski T, Zagórski Z. Results of Nd: YAG laser capsulotomy in posterior capsule opacification. Ann Univ Mariae Curie Sklodowska Med. 2002;57(1):357-63. PMID: 12898944

7. Pandey SK, Apple DJ, Werner L, Maloof AJ, Milverton EJ. Posterior capsule opacification: a review of the aetiopathogenesis, experimental and clinical studies and
در مطالعه حاضر كه بر خلاف اكثر مطالعات قبلى بلصورت

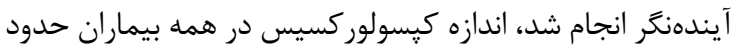

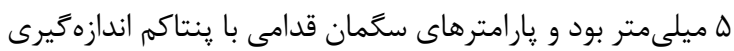

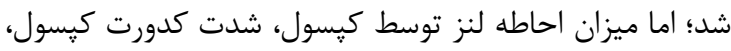

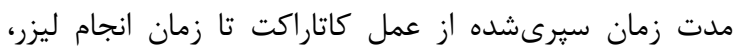
تفاوت در انرزى و تعداد اسياتهاى ليزر و دستخاه مورد استفاده

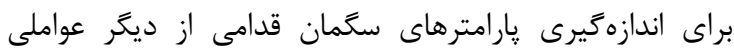

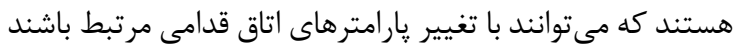
(كه در اين مطالعه به تفكيك مورد ارزيابى قرار نترفتهاند). بديهى است كه لحاظنمودن اين فاكتورها بهعنوان عوامل مخدوش كننده، استفاده از حجم نمونه بيشتر و يِيخيرى طولانى

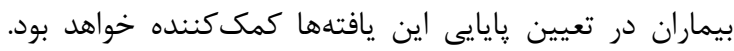

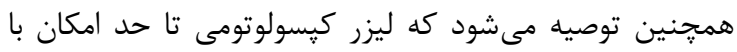

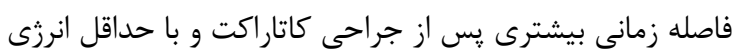

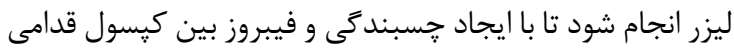
و خلفى عدسى از عوارض ناخواسته كيسولوتومى كاسته گردد.

نتيجه كيرى

عمل ياگ ليزر كيسولوتومى به طور معنى دارى باعث كاهش

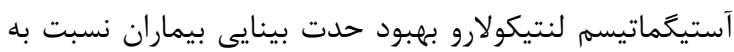
قبل از انجام عمل مىشود. تغيير در عمق اتاق قدامى مى تواند

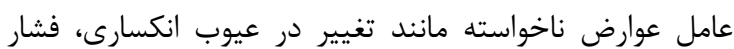
داخل جشمم و جابجايى لنز باشد.

\footnotetext{
تشكر و قلروفاذى

اين مقاله بركرفته از پاياننامه دكترى حرفهاى زيزشكى

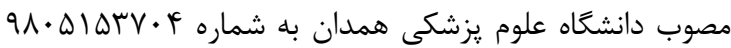

factors for prevention. Indian J Ophthalmol. 2004;52(2):99112. PMID: 15283214

8. Abhay RV, Shetal MR, Gauri DS. Posterior capsule opacification after lens implantation. Expert Rev Ophthalmol. 2013;8(2):141-9.

9. Billotte C, Berdeaux G. Adverse clinical consequences of neodymium: YAG laser treatment of posterior capsule opacification. J Cataract Refract Surg. 2004;30(10):206471. PMID: 15474815 DOI: $10.1016 /$ j.jers.2004.05.003

10. Aslam TM, Devlin H, Dhillon B. Use of Nd: YAG laser capsulotomy. Surv Ophthalmol. 2003;48(6):594-612. PMID: 14609706 DOI: 10.1016/j.survophthal.2003.08.002

11. Eliaçık M, Bayramlar H, Erdur SK, Demirci G, Gülkılık G. Anterior segment optical coherence tomography measurement after neodymium-yttrium-aluminum-garnet laser capsulotomy. Am J Ophthalmol. 2014;158(5):994-8. PMID: 25127700 DOI: 10.1016/j.ajo.2014.08.008

12. Khambhiphant B, Liumsirijarern C, Saehout $P$. The effect of $\mathrm{Nd}$ : YAG laser treatment of posterior capsule opacification on anterior chamber depth and refraction in pseudophakic eyes. Clin Ophthalmol. 2015;9:557-61. PMID: 25848207 DOI: $10.2147 / \mathrm{OPTH} . \mathrm{S} 80220$

13. Ozkurt YB, Sengör T, Evciman T, Haboğlu M. Refraction, intraocular pressure and anterior chamber depth changes after $\mathrm{Nd}$ : YAG laser treatment for posterior capsular opacification in pseudophakic eyes. Clin Exp Optom. 2009;92(5):412-5. PMID: 19549226 DOI: 10.1111/j.1444-0938.2009.00401.x 
14. Oztas Z, Palamar M, Afrashi F, Yagci A. The effects of Nd: YAG laser capsulotomy on anterior segment parameters in patients with posterior capsular opacification. Clin Exp Optom. 2015;98(2):168-71. PMID: 25195519 DOI: 10.1111/cxo.12205

15. Eslami F, Alizadeh M, Kosari F. Comparison of ultrasound and lenstar biometry methods in determining axial length and refractive error after cataract surgery. Avicenna J Clin Med. 2018;25(3):165-9. DOI: 10.21859 /ajcm.25.3.165

16. Moeini H, Eslami F, Rismanchian A, Akhlaghi MR, Najafianjaz A. Comparison of ultrasound and optic biometry with respect to eye refractive errors after phacoemulsification. J Res Med Sci. 2008;13(2):43-7

17. Zaidi M, Askari SN. Effect of Nd: YAG laser posterior capsulotomy on anterior chamber depth, Intraocular pressure, and refractive status. J Cataract Refract Surg. 2000;
26(8):1183-9.

18. Mortazavi SA, Eslami F, Atarzadeh H, Nasrollahi K, Ghoreishi SM. Evaluation of visual function improvement after ND: YAG laser posterior capsulotomy in patient with posterior capsule opacification. J Isfahan Med Sch. 2008;26(88):62-9

19. Rohani MR, Parhizkar M, Khalaghi H, Validad MH Refractive and anterior chamber parametric changes after Nd: YAG laser capsulotomy. Bina J Ophthalmol. 2013;18(4): 432-6. [Persian]

20. Findl O, Drexler W, Menapace R, Georgopoulos M, Rainer $\mathrm{G}$, Hitzenberger $\mathrm{CK}$, et al. Changes in intraocular lens position after neodymium: YAG capsulotomy. J Cataract Refract Surg. 1999;25(5):659-62. PMID: 10330641 DOI: 10.1016/s0886-3350(99)00010-3 